André Munzinger

\title{
Gemeinsame Welt denken
}

\author{
Bedingungen interkultureller Koexistenz bei Jürgen Habermas und Eilert Herms
}

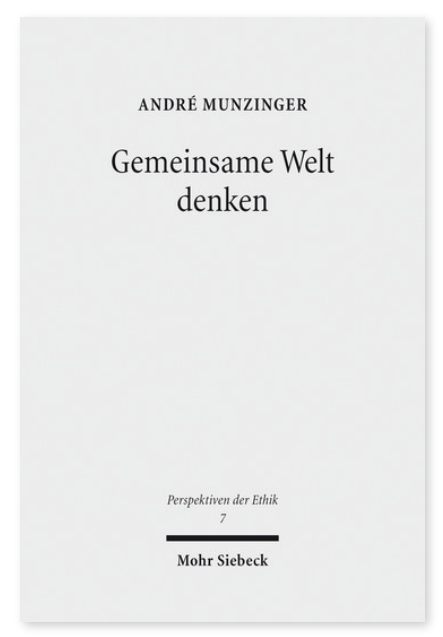

2015. XVIII, 385 Seiten. PE 7

ISBN 978-3-16-153420-1

DOI 10.1628/978-3-16-153420-1

eBook PDF $89,00 €$

ISBN 978-3-16-153419-5

fadengeheftete Broschur 89,00€
Wie können Menschen verschiedener Kulturen und Religionen friedlich zusammenleben? Auf welcher Grundlage lässt sich die gemeinsame Welt gestalten? Die Werke von Jürgen Habermas und Eilert Herms stehen für gegensätzliche Antworten auf diese Fragen: Für Habermas ist es die kommunikative Vernunft, die verbindet, für Herms dagegen die Erfahrung radikaler Perspektivität, die sich in unterschiedlichen Religionen manifestiert. Dieser Dissens ist produktiv: Vernunft und Religion, so die These von André Munzinger, stehen in einer komplementären Konkurrenz zueinander, weil sie auf unterschiedliche Weise auf die Einheit in der Vielfalt ausgerichtet sind. Friedliches Zusammenleben ist auf eine diskursive Verständigung über die weltanschaulichen Differenzen angewiesen, die in globalisierten Institutionen z. B. des Rechts, der Politik, des Wissens oder der Religion eingebettet werden muss.

André Munzinger Geboren 1972; 1995-98 Studium der Theologie in Bonn, Wuppertal, London; 2004 Promotion an der London School of Theology; 2012 Habilitation an der Evang.-Theol. Fakultät der Universität Bonn; ab 2012 Wissenschaftlicher Mitarbeiter und Coach an der Universität Oldenburg und Privatdozent an der Evang.-Theol. Fakultät der Universität Bonn, seit 2014 Professur für Systematische Theologie mit Schwerpunkt Ethik an der Christian-Albrechts-Universität zu Kiel.

etzt bestellen:

https://mohrsiebeck.com/buch/gemeinsame-welt-denken-9783161534201?no_cache=1

order@mohrsiebeck.com

Telefon: +49 (0)7071-923-17

Telefax: $+49(0) 7071-51104$ 